\title{
11. Testing Bubbles: Exuberance and collapse in the Shanghai A-share stock market
}

\author{
Zhenya Liu, Danyuanni Han and Shixuan Wang
}

\section{Introduction}

When a stock market bubble bursts, it can trigger financial crises that spread to the real economy. New and selectively complicated time-series methods are emerging that allow for better understanding of bubbles. In this chapter, we use the sup augmented Dickey-Fuller test (SADF) test developed by Phillips et al. (2011) and the generalised sup augmented Dickey-Fuller test (GSADF) test developed by Phillips et al. (2013) to identify bubbles in the Shanghai A-share stock market; the tests can also track a bubble's origination and termination dates. To our knowledge, this is the first time in the literature that the SADF and the GSADF have been applied to this stock market.

The study of speculative bubbles is a topic of long-standing interest in economics research. Many researchers have proposed various testing methods to analyse these dynamics from multiple perspectives. Lehkonen (2010) used the duration dependence test to examine weekly and monthly stock prices in China, and found that bubbles for Mainland China's stock markets are observable in weekly but not in monthly data. This result suggests that duration-dependent tests might not be appropriate for identifying bubbles in Mainland China. Yu et al. (2013) suggested combining the variance decomposition method with the dynamic autoregression method to obtain a measure of bubble risk. Unfortunately, their test methodology process is very tedious, which is not generally supported by economists.

Phillips et al. (2013) successfully developed a new test methodology for detecting multiple bubbles in continuous time- and date-stamping cycles, the GSADF, which is a generalised version of the SADF. The GSADF improves the flexibility of the rolling window of the SADF test. This improvement makes the test relatively suitable for multiple bubble phenomena with both a nonlinear structure and a break mechanism. Their method succeeded in correctly identifying famous episodes of exuberance and collapse over the period from January 1871 to December 2010 using Standard \& Poor's (S\&P) 500 stock market data. 
Such results suggest that the SADF and GSADF tests are potentially more powerful in identifying the exuberance and collapse of multiple bubbles in the Shanghai A-share stock market than other test methodologies, and we therefore adopt these methods in this chapter. The chapter is organised as follows: section two reviews the literature on bubble test methodologies. Section three provides an overview of the theoretical model. Section four introduces the model specifications and date-stamping strategies behind the SADF and GSADF tests. Section five discusses the testing data. The empirical testing results of the SADF and GSADF tests are reported in section six. Section seven analyses the evolution of each periodically collapsing bubble in the Shanghai A-share stock market, and section eight provides a conclusion.

\section{Literature review}

The concept of a rational bubble was originally proposed by Blanchard (1979a) based on his work using an overlapping generations model. If the elasticity of the current price with respect to the next period's expected price is smaller than one unity, there should exist a forward solution that takes the stationarity requirement into account, and so the rational expectation solution is conditional on the relationship between the current price and the expected future price (Blanchard 1979a). Blanchard (1979b) subsequently constructed models for detecting speculative bubbles that adopted rational expectation assumptions. Flood and Garber (1980) published the completed rational expectations model for testing the first existence of a price-level bubble. As required by the rational expectations model, bubbles appear when the current price is determined mainly by the change in the expected market price. The rational expectations model here becomes the theoretical basis for measuring market bubbles. In this way, Blanchard and Watson (1982) explain rational bubbles as the deviation of asset prices from the fundamental value by use of a dynamic forecasting model, which follows from the fact that speculative bubbles are not ruled by rational behaviour, even though rational behaviour has a real effect on market fundamentals and also modifies the behaviour of prices (Blanchard and Watson 1982). But with the interference of irrationality variables, it is not easy to find a high-power procedure to test rational stock market bubbles.

In general, most econometric methodologies that seek to detect bubbles rely on rational expectations theories and are differentiated by varying testing techniques. These different techniques, however, produce diametrically opposing results. Two different variance bounds tests (Shiller 1981; West 1987) reached the same conclusion: rejecting the null hypothesis of no bubbles. But Diba and Grossman (1988a) consider that mixed testing results produced by a cointegration test probably reflect the low power of the tests rather than the 
presence of explosive rational bubbles in stock prices. Diba and Grossman (1988a) and Flood and Hodrick (1990) concur that the rejection of a no-bubbles hypothesis cannot be used to confirm the existence of bubbles, because the composite null hypothesis in fact already contains bubbles-because bubbles are expected to emerge gradually, hence a variance bounds test is not well suited for testing for bubbles. Another problem is that the test methods proposed by Shiller (1981), West (1987) and Diba and Grossman (1988a) are also restricted to linear testing. But through Monte Carlo simulation, Evans (1991) finds that popular linear testing strategies cannot detect periodically collapsing bubbles since highly nonlinear periodically collapsing bubbles usually do not have integration and cointegration properties. Evans's (1991) findings served to inspire further work towards constructing nonlinear testing models for successfully detecting periodic bubble collapses.

Taylor and David (1998) proposed a bubble test based on non-cointegration test. Ahmed et al. (1999) use a vector autoregression model to examine nonlinearities in stock market movement in 10 Pacific Rim countries and districts, although they do not offer certainty that the estimated fundamentals are correct. After learning from the existing test failure, Wu (1997) proposes that if a bubble can be treated as an unobserved state vector in the state-space model, the Kalman filter technique should easily detect market bubbles. Using S\&P 500 stock market data, Wu (1997) explains many of the stock price deviations of the bull and bear markets of the twentieth century. Hall et al. (1999) suggest use of a generalised Dickey-Fuller (DF) test procedure that makes use of a class of Markov regime-switching models to achieve a nonlinear testing methodology. This method works because when the ADF regression parameters are allowed to switch values among different regimes, the ADF formulation will match the dynamic changing process of periodically collapsing bubbles. Kang (2010) opts for the smooth threshold autoregressive (STAR) model to identify bubbles in China's stock market. The empirical results show that the nonlinear motion of bubbles tracked by the STAR model closely links with real stock market volatility. Kang (2010) also acknowledges, however, that the STAR model cannot cope perfectly with nonlinear and asymmetrical dynamics of bubbles in China's stock markets.

More recently, Phillips et al. (2011) use a forward recursive right-sided unit root test to solve the issue proposed by Diba and Grossman (1988a). They conduct the DF statistics sequentially for date-stamping the origination and termination dates of bubbles. This new testing procedure is called the SADF test. Using the SADF test, Phillips et al. (2011) successfully document all explosive bubbles on the Nasdaq stock market in the 1990s. In the Monte Carlo experiment, the SADF test exhibits powerful superiority in detecting periodically collapsing bubbles among all tests from the study of Homm and Breitung (2012). Phillips et al. 
(2014) again express confidence in the recursive right-tailed ADF test, given its use in detecting mildly explosive or sub-martingale behaviour in the data as a form of market diagnostic alert.

Phillips et al. (2013) developed the GSADF test, which has an econometric detection mechanism similar to the SADF test, as both rely on a recursive righttailed ADF unit root test to detect periodically collapsing bubbles. The difference is that the SADF test has a relatively fixed window width with an identified starting point and changeable end point, while the GSADF test extends sample data coverage by a feasible rolling window size so as to overcome the weakness of the SADF test. This modification is very important. The SADF test is only able to identify a single bubble because of the fixed starting point design. The GSADF test design expands the detection range so that it is able to identify all episodes of exuberance and collapse in multiple bubbles. The GSADF test is, at this stage in the literature, likely to be the most advanced bubble detection strategy, which we will use for the Shanghai A-share stock market. We elaborate further in section four.

\section{Theoretical model background}

This section presents the basic theoretical background to models of bubble detection. Under the assumption of rational expectations and efficient markets, Lehkonen (2010) allows for deviations of stock prices from fundamental values, which are actually caused by rational rather than irrational traders. Blanchard and Watson (1982), Diba and Grossman (1988a) and Flood and Hodrick (1990) agree that deviation between the stock price and the fundamental value is a product of rationality-driven bubbles, and hence the size of the deviation is equivalent to the size of the bubble.

Under the efficient market hypothesis, the market will realise a 'no-arbitrage equilibrium' at a time when the expected return on risky assets is equal to the yield demanded by investors. We assume that the stock price at time $\mathrm{t}$ is $P_{t}$ and the stock dividend at time $\mathrm{t}+1$ is $D_{t+1}$. Then, $R_{t+1}$ is the return of an asset at time $\mathrm{t}+\mathrm{l}$ and is influenced by the changes in stock price and dividend. We thus have Equation 11.1.

Equation 11.1

$$
R_{t+1}=\frac{P_{t+1}-P_{t}+D_{t+1}}{P_{t}}=\frac{P_{t+1}+D_{t+1}}{P_{t}}-1
$$

Under rational expectations (Equation 11.2). 


\section{Equation 11.2}

$E_{t}\left(R_{t+1}\right)=r_{t+1}$

In Equation 11.2, $E_{t}$ denotes expectations mathematically given the information set at time $\mathrm{t} ; r_{t+1}$ is equal to the time-varying required rate of return (Equation 12.3).

\section{Equation 11.3}

$$
P_{t}=\frac{E_{t}\left(P_{t+1}+D_{t+1}\right)}{1+r_{t+1}}
$$

Equation 11.3 implies that the current stock price is equal to the sum of expected future prices and dividends at time $t+1$ divided by the required return rate. Using the iterative solution method, we can then solve the fundamental value of the asset under the equilibrium condition (Equation 12.4).

\section{Equation 11.4}

$P_{t}^{*}=\sum_{i=1}^{\infty} \frac{E_{t}\left(D_{t+i}\right)}{\prod_{j=1}^{i}\left(1+r_{t+j}\right)}$

From this, we can derive a new formula containing a bubble variable (Equation 12.5).

\section{Equation 11.5}

$$
P_{t}=P_{t}^{*}+B_{t}
$$

In Equation 11.5, $B_{t}$ is the rational price bubble and $B_{t}=E_{t}\left(B_{t+1}\right) /\left(1+r_{t+1}\right)$. Equation 11.5 demonstrates that bubble factor, $B_{t^{\prime}}$ drives the stock price, $P_{t^{\prime}}$ to deviate from the fundamentals, $P_{t}^{*}$. On average, this bubble factor discounts at the required rate of return, $r_{t+1}$. Flood and Hodrick (1990) rewrite the bubble equation as Equation 11.6.

\section{Equation 11.6}

$$
B_{t+1}=B_{t} *\left(1+r_{t+1}\right)+B_{t+1}
$$

In Equation 11.6, $B_{t+1}=B_{t+1}-E_{t}\left(B_{t+1}\right) . B_{t}$ is a stock price bubble and $B_{t+1}$ reflects innovation in the bubble, which has a mean of zero.

In the rational speculative bubble model, Blanchard and Watson (1982) describe the formation and bursting process of bubbles as follows (Equation 11.7). 
Equation 11.7

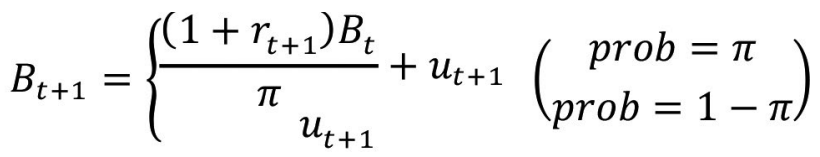

From the above mathematical expressions, we can observe that the bubble factor, $B_{t^{\prime}}$ grows at a fixed rate with probability $\pi$ and collapses with probability $1-\pi$, back to the initial value, $u_{t+1}$, where $u_{t+1}$ is a random variable with a mean of zero. If the bubble does not collapse, investors can realise a return of $r_{t+1}$, which equates compensation and risk values. In other words, when investors want to be compensated for overpayment (over the fundamental price) by future appreciation of the bubble component, the bubble component must be positive.

When rational bubbles occur in the stock market, this will induce market exuberance or financial crash. Phillips et al. (2013) conclude that financial exuberance derives from pricing errors or the deviation of stock price in response to fundamentals. In the literature, there are two conditions resulting in market exuberance. In the view of Phillips et al. (2013), the first condition is that market exuberance arises from behavioural factors and the second condition relates to the fact that fundamentals themselves might be highly sensitive to changes in the discount rate; its high sensitivity therefore forces the increases in the price to mimic the inflation of a bubble.

Evans (1991) believes that the standard linear test methodology fails to identify periodically collapsing bubbles in empirical testing, and that only nonlinear bubble detection models can avoid the aforementioned mistakes. Since then, Evans (1991) has suggested describing periodically collapsing bubbles in the following way (Equation 11.8).

\section{Equation 11.8}

$$
\begin{gathered}
B_{t+1}=(1+r) B_{t} u_{t+1} \text { if } B_{t} \leq \alpha \\
B_{t+1}=\left[\delta+\pi^{-1}(1+r) \theta_{t+1} *\left(B_{t}-(1+r)^{-1} \delta\right)\right] u_{t+1} \text { if } B_{t}>\alpha
\end{gathered}
$$

In Equation 11.8, $\delta$ and $\alpha$ are positive parameters with $0<\delta<(1+r) \alpha, u_{t+1}$ is an exogenous independently and identically distributed positive random variable with $E_{t} u_{t+1}=1$ and identically distributed Bernoulli process (independent of $u$ ), which takes the value 1 with probability $\pi$ and 0 with probability $1-\pi$, where $0<\pi \leq 1$. If $B_{t} \leq \alpha$, the bubble will continually grow at a mean rate $(1+r)$. But if $B_{t}>\alpha$, the bubble will rapidly increase at an explosive rate, $\pi^{-1}(1+r)$, and it has a probability of $1-\pi$ to collapse in each period. Once a bubble bursts, it drops back to the mean value, $\delta$, and the process begins again. Hence, the evolution of bubbles is cyclical and recursive. Moreover and briefly, when $\pi$ 
is close to 1 , the unit root test can locate the existence of a bubble. When $\pi$ gradually becomes smaller, the unit root test loses its detection power, owing to the fact that when $\pi$ contracts, the explosiveness of bubble component $B_{t}$ becomes less significant. At this moment, the unit root test no longer works.

To effectively detect the explosiveness of a bubble using a unit root test, Phillips et al. (2011) adopt the recursive regression technique and the right-sided unit root test. These are more useful for detecting mild explosiveness or submartingale behaviour than the left-sided unit root test. The SADF test (Phillips et al. 2011) can directly test the stock price without calculating the fundamentals and rapidly capture the origin and terminus of multiple bubbles. In the light of the SADF test, Phillips et al. (2013) modify the test model to improve the flexibility and accuracy of test methodology. This new test methodology is referred to as the generalised sup ADF (GSADF) test. In the next section, the model specifications and date-stamping strategies of the SADF and GSADF tests will be introduced in detail.

\section{Model specifications and date-stamping strategies of the SADF and GSADF tests}

\section{Model specifications}

For the asset pricing equation for detecting financial bubbles, here we adopt the same equation as Phillips et al. (2013) (Equation 11.9).

Equation 11.9

$P_{t}=\sum_{i=0}^{\infty}\left(\frac{1}{1+r_{f}}\right)^{i} E_{t}\left(D_{t+i}+U_{t+i}\right)+B_{t}$

In Equation 11.9, $P_{t}$ is the after-dividend price, $D_{t}$ is the dividend, $R_{f}$ is the risk-free interest rate and $B_{t}$ is the bubble factor. Equation 11.9 is equivalent to Equation 11.4 and Equation 11.5, plus a new variable, $U_{t^{\prime}}$ denoting the unobservable fundamentals. We know that $B_{t}$ satisfies the sub-martingale property, as follows (Equation 11.10).

Equation 11.10

$E_{t}\left(B_{t+1}\right)=\left(1+r_{f}\right) B_{t}$

If there is no bubble at time $t, B_{t}=0$, thus we have Equation 11.11. 
Equation 11.11

$P_{t}=\sum_{i=0}^{\infty}\left(\frac{1}{1+r_{f}}\right)^{i} E_{t}\left(D_{t+i}+U_{t+i}\right)$

The degree of non-stationarity of the asset price is decided by the $D_{t}$ and $U_{t}$. When $U_{t}$ is at $I(1)$ and $D_{t}$ is stationary after differencing, empirical evidence of explosive behaviour in asset prices may be used to conclude the existence of bubbles (Phillips et al. 2013).

There is general agreement that bubble phenomena can occur during periods of market exuberance and collapse. Disagreement, however, centres on how to measure and predict the bubble. The SADF and GSADF tests measure the bubble based on the price-dividend ratio. Their derivation processes are taken from the model specification of Campbell and Shiller (1988).

Here we first take the logarithm of Equation 11.3 (Equation 11.12).

Equation 11.12

$p_{t}=\kappa+\rho p_{t+1}+(1-\rho) d_{t+1}-r_{t+1}$

Here, $\kappa=-\log (\rho)-(1-\rho) \log (1 / \rho-1)$. Note that $\rho=1 /\left[1+e^{\overline{p-d}}\right]$ with $\overline{p-d}$ as the average price-dividend ratio. Variables $p_{t^{\prime}} d_{t}$ and $r_{t}$ are natural logarithmic values of $P_{t^{\prime}} D_{t}$ and $R_{t}$. Solving Equation 11.12 by forward iteration and taking expectations yields Equation 11.13, which includes the logarithm of the price-dividend ratio (Equation 11.13).

\section{Equation 11.13}

$p_{t}-d_{t}=\frac{\kappa}{1-\rho}+\sum_{i=0}^{\infty} \rho^{i} E_{t}\left(\Delta d_{t+1+i}-r_{t+1+i}\right)+\lim _{i \rightarrow \infty} \rho^{i} E_{t}\left(p_{t+i}-d_{t+i}\right)$

When we set $p_{t}^{f}=\frac{\kappa}{1-\rho}+\sum_{i=0}^{\infty} \rho^{i} E_{t}\left(\Delta d_{t+1+i}-r_{t+1+i}\right)$ as the fundamental component and $b_{t}=\lim _{i \rightarrow \infty} \rho^{i} E_{t}\left(p_{t+i}-d_{t+i}\right)$ as the rational bubble component, we arrive at Equation 11.14.

Equation 11.14

$$
p_{t}-d_{t}=p_{t}^{f}+b_{t}
$$


Further, $E_{t}\left(b_{t+1}\right)=\frac{1}{\rho} b_{t}=[1+\exp (\overline{p-d})] b_{t}$, with $g=[1+\exp (\overline{p-d})]>0$. And the logarithm of the bubble component has the growth rate $g$.

In the absence of a bubble component, condition $b_{t}=0$, since $p_{t}=d_{t}+p_{t}^{f}$. From the equation of $p_{t}^{f}$, we can obtain Equation 11.15.

Equation 11.15

$$
d_{t}-p_{t}=-p_{t}^{f}=-\frac{\kappa-r}{1-\rho}-\sum_{i=0}^{\infty} \rho^{i} E_{t}\left(\Delta d_{t+1+i}\right)
$$

When $p_{t}^{f}$ is ruled out from stock price $p_{t^{\prime}}$ the residual component should be stationary. If the residual part is non-stationary, this indicates there is a bubble in $p_{t}$.

When explosive bubbles are presented (that is, $b_{t} \neq 0$ ), $p_{t}$ is determined by $b_{t^{\prime}}$ irrespective of whether $d_{t}$ is an integrated process $I(1)$ or a stationary process $I$ (0) (Phillips et al. 2011). In other words, the stock price follows a nonstationary process. Thus, the dynamics of $p_{t}-d_{t}$ are determined by $p_{t}^{f}$ and $b_{t}$. If the variables in $p_{t}^{f}$ have stationary process $I(0)$, there is only $b_{t}$ remaining with a relationship with the explosiveness in $p_{t}-d_{t}$. That means a test for the explosive behaviour of $p_{t}-d_{t}$ is also a test for the bubble component $b_{t}$.

Although the SADF and GSADF tests share a common testing variable, the price-dividend ratio, the difference between them is at the rolling window setting. The basic idea behind the GSADF test is specifically to change the rolling window widths, first, by forward recursive progression, and then get the SADF test sequence, and, last, to find the maximum value from its SADF test sequence and compare this with the corresponding SADF critical value to decide whether to reject the null hypothesis. Phillips et al. (2013) assume a random walk (or, more generally, a martingale) process with an asymptotically negligible drift. The form is written as Equation 11.16.

\section{Equation 11.16}

$$
y_{t}=c T^{-\lambda}+\theta y_{t-1}+u_{t}, u_{t} \sim \text { i.i.d. } N\left(0, \sigma^{2}\right), \theta=1
$$

In Equation 11.16, $\mathrm{c}$ is constant, $\lambda>1 / 2$ serves as a localising coefficient that controls the magnitude of the drift and $\mathrm{T}$ is the sample size with $T \rightarrow \infty$. Obviously, this equation is a unit root procedure without a trend item, but with a gradually disappearing intercept. 
If the initial sample proportion of the recursive approach is $r_{0}$ and the total sample is $T$, the test sample size is expressed as $t=\left\lfloor T r_{0}\right\rfloor$, where $\lfloor\cdot\rfloor$ takes the integer part of the input variable. From the first observation, Phillips et al. (2011) set the recursive right-sided unit root test with sample data to $t=\lfloor T r\rfloor$. The SADF test relies mainly on recursive calculations of the ADF statistics with a fixed starting point and a changeable width window. Suppose that $r_{1}$ is the starting point of the test and $r_{2}$ is the end point, $r_{\mathrm{w}}=r_{2}-r_{1}$ is the window size of the regression. The empirical model is defined as Equation 11.17.

\section{Equation 11.17}

$$
\Delta y_{t}=\alpha_{r_{1}}^{r_{2}}+\beta_{r_{1}}^{r_{2}} y_{t-1}+\sum_{i=1}^{k} \psi_{r_{1}, i}^{r_{2}} \Delta y_{t-i}+\varepsilon_{t}
$$

In Equation 11.17, $k$ is the lag order and $\varepsilon_{t} \sim$ i.i.d. $\left(0, \sigma_{r_{1}, r_{2}}^{2}\right) . A D F_{r_{1}}^{r_{2}}$ denotes the ADF statistic value ( $\mathrm{t}$-value) of the equation.

The SADF test requires a repeated ADF test on a forward expanding sample sequence. The test result obtained is the sup value of the corresponding ADF statistics sequence (Phillips et al. 2013). Under this model specification, the starting point is fixed at $r_{0^{\prime}}$ in contrast, the end point, $r_{2^{\prime}}$ can freely expand from $r_{0}$ to 1 . The SADF statistic can be written as Equation 11.18 .

Equation 11.18

$$
\operatorname{SADF}\left(r_{0}\right)=\sup _{r_{2} \in\left[r_{0}, 1\right]} A D F_{0}^{r_{2}}
$$

The GSADF test is distinct from the SADF test in that it allows the starting point and the end point to change simultaneously. Therefore, the starting point, $r_{1}$, can vary within the range $\left[0, r_{2}-r_{0}\right]$ and the size of window width, $r_{w^{\prime}}$ also flexibly shifts within the bounds of $r_{1}$ and $r_{2}$. Since this modification extends the range of subsample data, the GSADF test is more accurate for detecting multiple bubbles than the SADF test. The GSADF test is defined as follows (Equation 11.19).

\section{Equation 11.19}

$$
\begin{aligned}
& G S A D F\left(r_{0}\right)=\quad \sup \left\{A D F_{r_{1}}^{r_{2}}\right\} \\
& r_{2} \in\left[r_{0}, 1\right] \\
& r_{1} \in\left[0, r_{2}-r_{0}\right]
\end{aligned}
$$

The asymptotic GSADF distribution might be affected by the smallest window width, $r_{0^{\prime}}$ according to the limit theory of the SADF test. As a result, the starting point, $r_{0}$, is determined by $\mathrm{T}$, which is the total number of sample observations. 
Phillips et al. (2013) summarise the negative relationship between $r_{0}$ and $\mathrm{T}$. If $\mathrm{T}$ is small, $r_{0}$ needs to be large enough to ensure there are enough observations for adequate initial estimation. If $\mathrm{T}$ is large, $r_{0}$ can be set as a smaller number so that the test does not miss any opportunity to detect an early explosive episode.

\section{Data-stamping strategies}

We summarise the data-stamping strategies used by Phillips et al. $(2011,2013)$ for the SADF test and the GSADF test.

To detect bubbles, an information set is defined as $I_{\left[T_{r}\right]}=\left\{y_{1}, y_{2}, \ldots, y_{\left[T_{r}\right]}\right\}$. In the current information set, $I_{\left[T_{r}\right]}$, this could include multiple bubbles, a single bubble or no bubble. Phillips et al. (2011) propose a backward SADF test on $I_{\left[T_{r}\right]}$ to enhance the accuracy of bubble detection and to avoid pseudo stationary behaviour. The backward SADF test has the same arithmetical logic as the GSADF test, except for having a different test direction. Specifically, the backward SADF test chooses a fixed end point at $r_{2^{\prime}}$ which is the opposite of the forward SADF test, which sets a fixed starting point of $r_{0}$. To this end, the starting point of the backward SADF test becomes a changeable point varying from 0 to $r_{2}-r_{0}$. The backward SADF statistic can accordingly be defined as Equation 11.20.

\section{Equation 11.20}

$$
B S A D F_{r_{2}}\left(r_{0}\right)=\sup _{r_{1} \in\left[0, r_{2}-r_{0}\right]}\left\{A D F_{r_{1}}^{r_{2}}\right\}
$$

If $B S A D F_{r_{2}}\left(r_{0}\right)$ is bigger than the corresponding critical value of the standard ADF statistic at time $T r_{2}$, this time point, denoted by $T r_{e^{\prime}}$ is identified as the start date of a bubble. If, after time $\left\lfloor T \hat{r}_{e}\right\rfloor+\log (T)$, is smaller than the critical value of the standard ADF statistic, this is the termination date of the bubble denoted by $\left\lfloor T r_{f}\right\rfloor$. Phillips et al. (2011) impose a condition that the duration of a bubble should be longer than a slowly varying quantity, $L_{T}=\log (T)$. The condition nicely excludes short-term volatility in the fitted autoregressive coefficient and takes the data frequency into consideration (Phillips et al. 2013). From the above discussion, we can thus use the following formulations to represent the origination and termination times of a bubble (Equations 12.21 and 12.22).

\section{Equation 11.21}

$$
\widehat{r}_{e}=\inf _{\mathrm{r}_{2} \in\left[\mathrm{r}_{0}, 1\right]}\left\{r_{2}: A D F_{r_{2}}>c v_{r_{2}}^{\beta T}\right\}
$$


Equation 11.22

$\widehat{r}_{f}=\inf _{\mathrm{r}_{2} \in\left[\widehat{\mathrm{r}_{\mathrm{e}}}+\log (\mathrm{T}) / \mathrm{T}, 1\right]}\left\{r_{2}: A D F_{r_{2}}<c v_{r_{2}}^{\beta_{T}}\right\}$

In these equations, $c v_{r_{2}}^{\beta_{T}}$ is the $100^{*}\left(1-\beta_{T}\right) \%$ critical value of the ADF statistic based on $\left\lfloor T r_{2}\right\rfloor$ observations.

Similarly, when Equation 11.20 relaxes the limitation of supremum value $r_{2^{\prime}}$ in this way, $r_{2}$ has a feasible range from $r_{0}$ to 1 . We obtain the date-stamping strategy of the GSADF test (Equation 11.23).

Equation 11.23

$$
G S A D F\left(r_{0}\right)=\sup _{\mathrm{r}_{2} \in\left[\mathrm{r}_{0}, 1\right]}\left\{B S A D F_{r_{2}}\left(r_{0}\right)\right\}
$$

The explosiveness observation of bubbles for the GSADF test is based on the backward SADF statistic, $B S A D F_{r_{2}}\left(r_{0}\right)$. Phillips et al. (2013) assume that the interval time between the origination date and the termination date is $\left\lfloor T \widehat{r}_{e}\right\rfloor+\delta \log (T)$, where $\delta$ is a frequency dependent parameter. The estimated equations of the bubble period under the GSADF test are Equations 12.24 and 12.25 .

\section{Equation 11.24}

$$
\widehat{r_{e}}=\inf _{\mathrm{r}_{2} \in\left[\mathrm{r}_{0}, 1\right]}\left\{r_{2}: B S A D F_{r_{2}}\left(r_{0}\right)>s c v_{r_{2}}^{\beta T}\right\}
$$

\section{Equation 11.25}

$$
\widehat{r}_{f}=\inf _{\mathrm{r}_{2} \in\left[\widehat{\mathrm{r}_{\mathrm{e}}}+\delta \log (\mathrm{T}) / \mathrm{T}, 1\right]}\left\{r_{2}: B S A D F_{r_{2}}\left(r_{0}\right)<s c v_{r_{2}}^{\beta_{T}}\right\}
$$

Formally, $s c v_{r_{2}}^{\beta_{T}}$ is the $100\left(1-\beta_{T}\right) \%$ critical value of the SADF statistic on the basis of $\left\lfloor\mathrm{Tr}_{2}\right\rfloor$ observations. The significance level, $\beta_{T^{\prime}}$ has an opposite approach with the sample size, $\mathrm{T}$. If $\mathrm{T}$ goes to zero, the significant level, $\beta_{T^{\prime}}$ moves to infinity. If the sample size, $\mathrm{T}$, approaches infinity, $\beta_{T}$ goes to zero. 


\section{The data}

The empirical data employed are the price index of the Shanghai A-share stock market and the dividend yield of the 1,061 listed companies in the Shanghai A-share stock market. The frequency of our data is monthly. Before 2000, most companies listed on the Shanghai A-share stock market did not pay out dividends, so these data are unavailable. Hence, the sample period starts from January 2000 to July 2015. Specifically, the monthly dividend yield time series of the Shanghai A-share stock market is calculated by summing the dividend yields of 1,061 listed companies. Then, the price-dividend ratio time series is calculated to reflect the relationship between the asset price and market fundamentals. All data are downloaded from Datastream.

\section{Shanghai A-Share Stock Market}

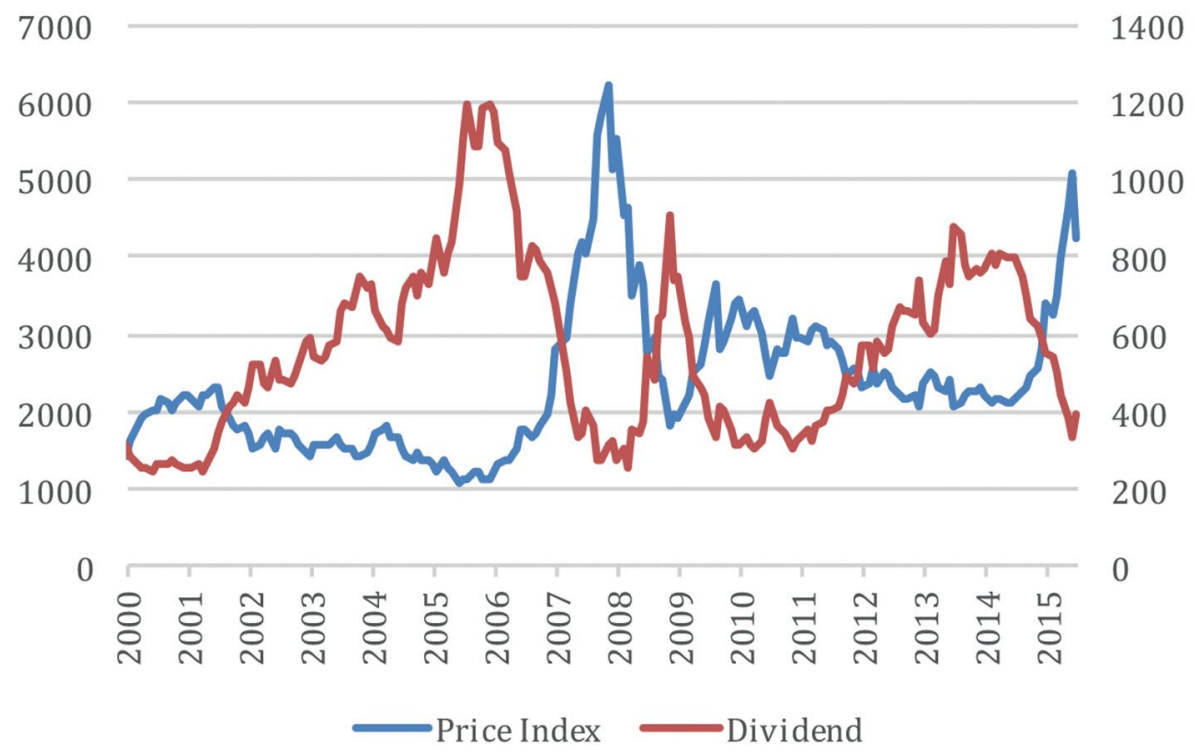

Figure 11.1 Time series of the price index (left axis) and dividend yield (right axis) of the Shanghai A-share stock market

Source: Datastream.

In Figure 11.1, there are two series. The blue line denotes the evolution of the price index. Primarily, the Shanghai A-share stock price index was stable from January 2000 to January 2006 and rose suddenly to 6,395.75 points on 16 October 2007, before rapidly dropping to 2,000 points in September 2008. After experiencing this period of volatility, the A-share market maintained a 
period of relatively stable fluctuation for six years, and began to enter another period of rapid increase in October 2014. The red line represents the dividend yield and shows a pattern that is generally opposite to that of the blue line. When the stock price increases, the dividend yield decreases, and vice versa.

20

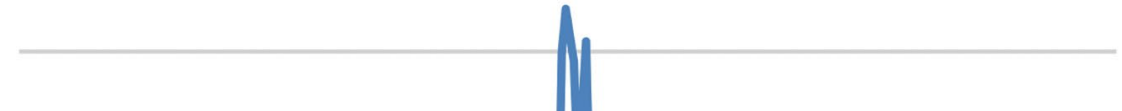

15

10

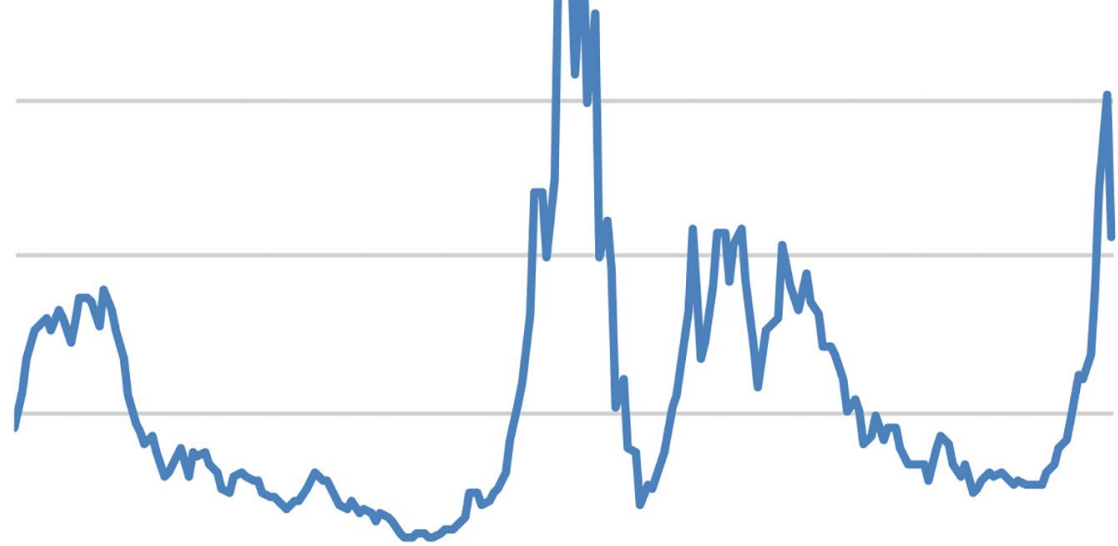

0

○

Figure 11.2 Price-dividend ratio of the Shanghai A-share market

Source: Datastream.

Figure 11.2 displays our testing data, the price-dividend ratio of the Shanghai A-share market, from January 2000 to July 2015. Generally, the Shanghai A-share price-dividend ratio fluctuated dramatically during our sample period. Before 2006, it gradually decreased and then abruptly jumped more than 20 in 2007. After the Global Financial Crisis in 2008, the price-dividend ratio contracted sharply to around three. During 2009-12, it fluctuated between 4 and 11, and started to climb again until 2014. 


\section{Empirical testing of the SADF and GSADF tests}

\section{The SADF test}

Using Eviews 8.0 software, we apply the SADF test to price-dividend ratio time series. The results are presented in Table 11.1.

Table 11.1 Critical values of the SADF test

\begin{tabular}{|l|l|c|c|}
\hline & & Statistics & P-value \\
\hline SADF & & 2.815 & 0.035 \\
\hline Test critical values & $99 \%$ level & 7.373 & \\
\hline & $95 \%$ level & 2.232 & \\
\hline & $90 \%$ level & 1.672 & \\
\hline
\end{tabular}

Notes: Critical values of the SADF test are calculated from a Monte Carlo simulation with 2,000 replications (sample size 187). The initial window size is four.

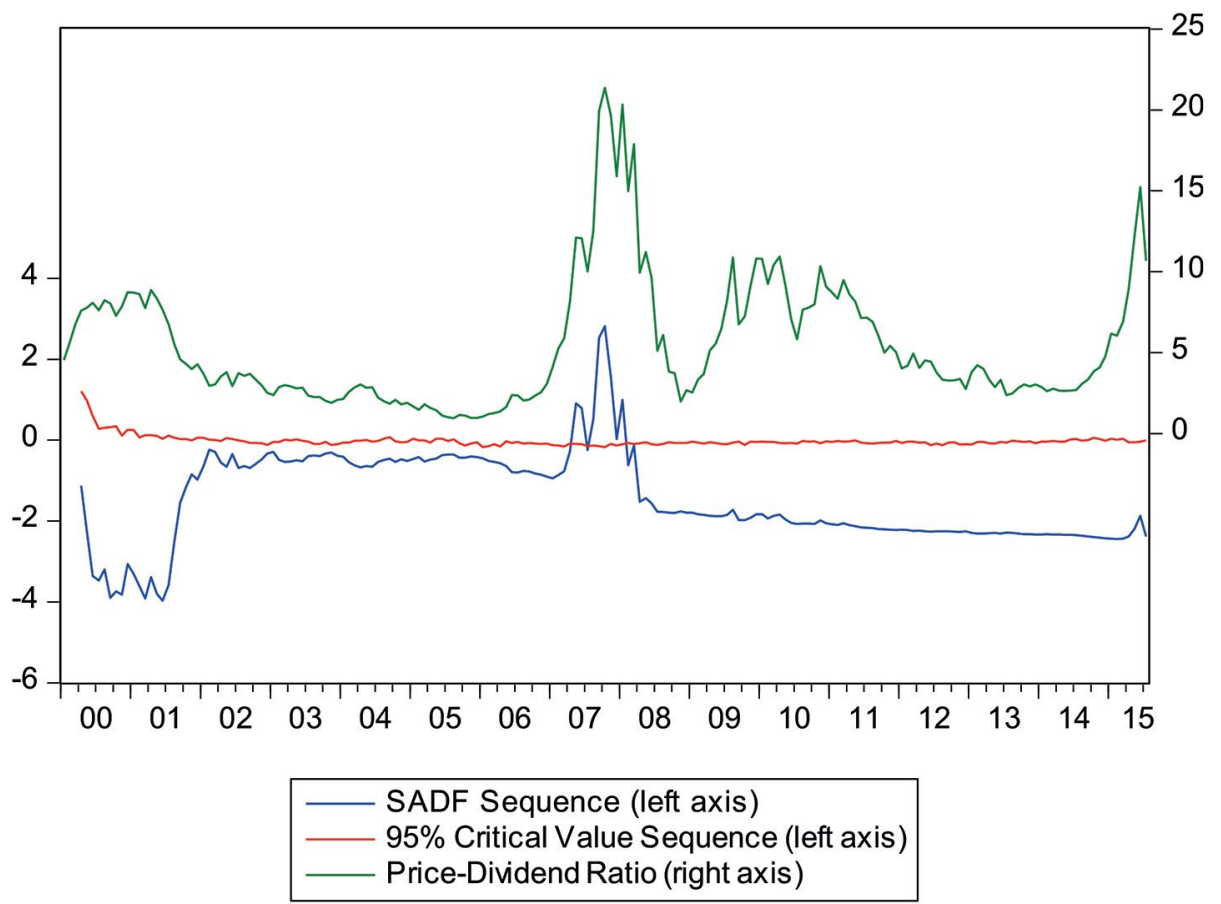

Figure 11.3 Date-stamping bubble periods in the Shanghai A-share modified price-dividend ratio: The SADF test

Source: Datastream. 
Table 11.1 shows that the SADF statistic value, 2.815 , is greater than the critical values at the 95 per cent and 90 per cent confidence levels. This indicates that we cannot reject the null hypothesis below a 95 per cent confidence level and, in other words, that the Shanghai A-share stock market is characterised by periodic bubbles. From Figure 11.3, it is evident that the blue line exceeds the red line, which indicates one periodic collapsing bubble occurred from March 2007 to February 2008.

\section{The GSADF test}

We applied the GSADF test to the price-dividend ratio (Table 11.2).

Table 11.2 Critical values of the GSADF test

\begin{tabular}{|l|c|c|c|}
\hline & & Statistics & P-value \\
\hline GSADF & & 35.735 & 0.011 \\
\hline Test critical values & $99 \%$ level & 36.403 & \\
\hline & $95 \%$ level & 14.180 & \\
\hline & $90 \%$ level & 10.080 & \\
\hline
\end{tabular}

Notes: Critical values of the GSADF test are calculated from a Monte Carlo simulation with 2,000 replications (sample size 187). The initial window size is four.

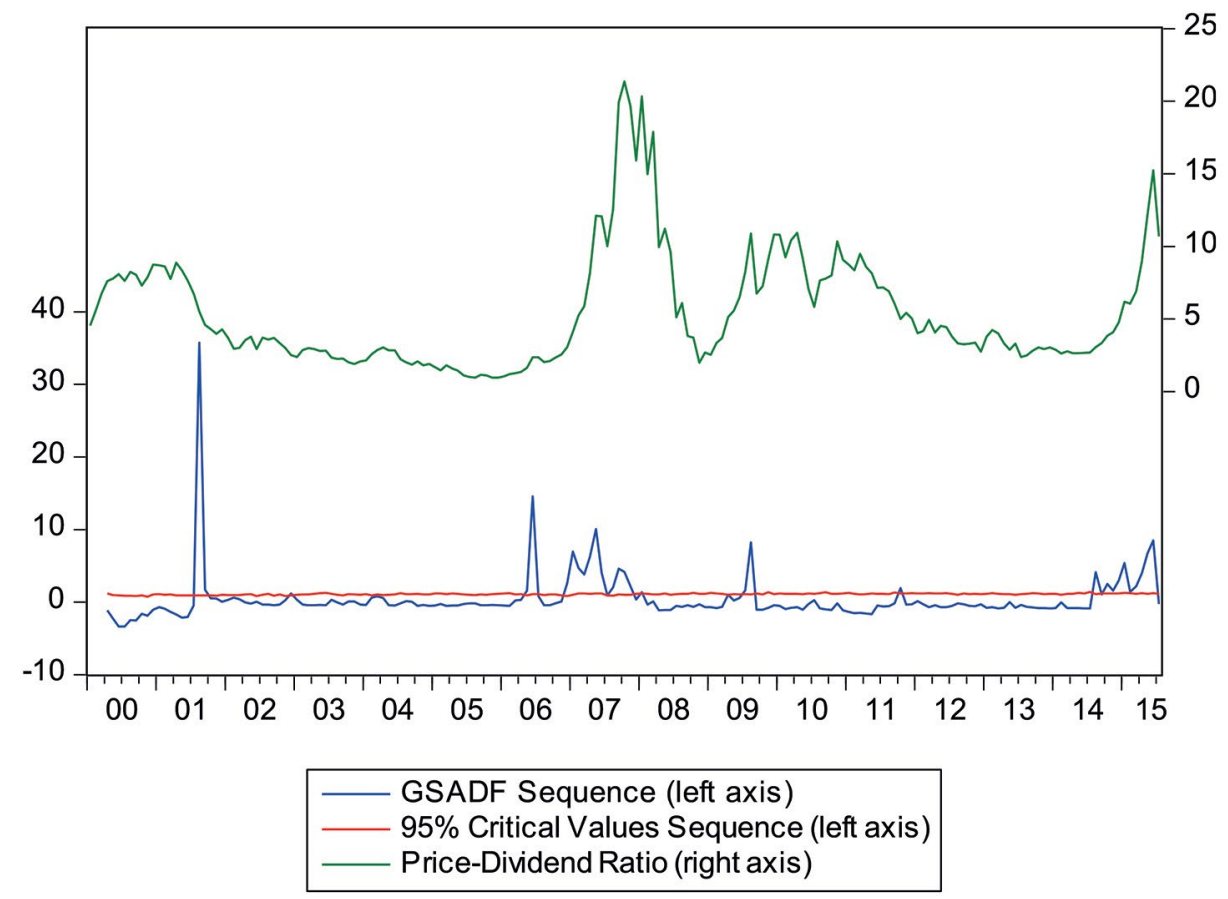

Figure 11.4 Date-stamping bubble periods in the Shanghai A-share modified price-dividend ratio: The GSADF test 
From Table 11.2, we see that the GSADF statistic obtained from sample data is 35.74, which is bigger than the two critical values at the 5 per cent and 10 per cent significance levels. Thus, we can reject the null hypothesis of no bubbles. And, in fact, Figure 11.4 clearly shows there were three periodically collapsing bubbles between January 2000 and July 2015.

The bubble between June and September 2001 had the shortest duration, which was possibly the result of media attention, government intervention or some other factor. Particularly, this bubble increase arose from positive news published by the China Securities Regulatory Commission (CSRC) that the B-share stock market was to officially open to domestic investors from February 2001. With the encouragement of this policy, the Shanghai and Shenzhen stock indexes rose together. The later collapse was also provoked by media reports - but this time, by bad news. The CSRC announced the issuance of a listed company management approach and a plan to reduce state-owned shares. This cycle of exuberance and collapse was therefore entirely manipulated by the CSRC, embodying the characteristic of a 'policy market'. Given there were no serious consequences, it is possible for the CSRC to deliberately guide this volatility. In the next section, to make our analysis more meaningful, we neglect the small, short bubble and focus on two significant periodically collapsing bubbles - namely, the subprime mortgage crisis bubble (October 2006 - January 2009) and the new bubble period (May 2014 - July 2015).

\section{Analysis of the exuberance and collapse of multiple bubbles}

\section{The subprime mortgage crisis bubble period (October 2006 - January 2009)}

Under the impetus of expectations of renminbi appreciation and the sharesplit reform policy, the Shanghai A-share stock market began a slow upward trend in the first half of 2006. By June 2006, the stock price had already risen to the critical 1,700 points level. As the stock market had just bailed out a bear market at that time, the A-share index maintained around 1,700 points for three months. Starting in October 2006, easing monetary policy and looser credit policy created a large amount of liquid and ideal funds, which helped to instigate a flood of investment in the stock market. The Shanghai A-share stock market provided an appealing investment channel for domestic individual investors. Consequently, the Shanghai A-share index kept increasing strongly and finally broke through 6,000 points in November 2007. In fact, in 2006 and 
2007, the Shanghai A-share stock price grew by as much as 80 per cent every year. For comparison, in same period, the S\&P 500 stock price increased by only about 20 per cent.

Table 11.3 compares the monthly growth rates of the Shanghai A-share price index and the S\&P 500. The Shanghai A-share price index is much more volatile than the S\&P 500 and generally had a much higher monthly growth rate during this bubble period. It shows that the Shanghai A-share price index maintained an average monthly growth rate of 8.5 per cent, and the highest growth rate reached was 27.4 per cent, in January 2007. The highest stock price, in November 2007, was 4.1 times the lowest point, which was in May 2006. The price-to-earnings (PE) ratios of many stocks were over 100 per cent. Such a high $\mathrm{PE}$ ratio requires a stronger earnings growth rate and a higher return on equity (ROE). Typically, a ROE sits at around 10 per cent, but the average ROE of Shanghai A-share listed companies is only 6.9 per cent. From the perspective of the PE ratio and the ROE, the stock price has greatly deviated from the listed companies' fundamental value.

Table 11.3 Shanghai A-share price index and S\&P 500 and their monthly growth rates

\begin{tabular}{|c|c|c|c|c|}
\hline $\begin{array}{l}\text { Period (first day } \\
\text { of month) }\end{array}$ & $\begin{array}{c}\text { Shanghai A-share } \\
\text { price index }\end{array}$ & $\begin{array}{c}\text { Monthly growth } \\
\text { rate (\%) }\end{array}$ & S\&P 500 & $\begin{array}{c}\text { Monthly growth } \\
\text { rate (\%) }\end{array}$ \\
\hline May-06 & $1,511.7$ & - & 1,305.2 & 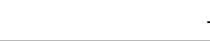 \\
\hline Jun-06 & $1,769.6$ & 17.1 & $1,285.7$ & -1.5 \\
\hline Jul-06 & $1,784.5$ & 0.8 & $1,280.2$ & -0.4 \\
\hline Aug-06 & $1,682.5$ & -5.7 & $1,270.9$ & -0.7 \\
\hline Sep-06 & $1,720.5$ & 2.3 & $1,311.0$ & 3.2 \\
\hline Oct-06 & $1,840.3$ & 7.0 & $1,331.3$ & 1.5 \\
\hline Nov-06 & $1,949.8$ & 6.0 & $1,367.8$ & 2.7 \\
\hline Dec-06 & $2,208.9$ & 13.3 & 1,396.7 & 2.1 \\
\hline Jan-07 & $2,815.1$ & 27.4 & $1,418.3$ & 1.5 \\
\hline Feb-07 & 2,926.8 & 4.0 & $1,445.9$ & 1.9 \\
\hline Mar-07 & $2,937.8$ & 0.4 & $1,403.2$ & -3.0 \\
\hline Apr-07 & $3,418.7$ & 16.4 & $1,424.6$ & 1.5 \\
\hline May-07 & $4,035.1$ & 18.0 & $1,486.3$ & 4.3 \\
\hline Jun-07 & $4,197.1$ & 4.0 & $1,536.3$ & 3.4 \\
\hline Jul-07 & $4,027.1$ & -4.1 & $1,519.4$ & -1.1 \\
\hline Aug-07 & $4,510.8$ & 12.0 & $1,465.8$ & -3.5 \\
\hline Sep-07 & $5,587.3$ & 23.9 & $1,474.0$ & 0.6 \\
\hline Oct-07 & $5,827.7$ & 4.3 & $1,547.0$ & 5.0 \\
\hline Nov-07 & $6,209.4$ & 6.6 & $1,508.4$ & -2.5 \\
\hline
\end{tabular}

Source: Datastream. 
To reduce the risk of a stock market crash, Chinese regulatory authorities imposed policies that sought to reduce the explosiveness of bubbles in the stock market. For example, the People's Bank of China (PBC) has raised the renminbi deposit reserve rate 10 times since the beginning of 2007. That year, the statutory deposit reserve rate increased from 9 per cent to 13 per cent. However, the rising deposit reserve rate did not decrease excessive liquidity in the stock market. A large volume of hot money continued to flow into the Shanghai A-share stock market, driving the stock price continuously up. Besides currency appreciation supporting the value of the renminbi-denominated A-share stock market, the price increases were driven largely by expectations of renminbi appreciation. Compared with other investor markets, the stock market has provided a relatively quick and easy way to make money, especially due to the low barriers to entrance and exit.

At the end of 2007, global financial turbulence caused major international stock markets to fall sharply. From November 2007 to January 2009, the Shanghai A-share stock price fell 224.8 per cent, from 6,209 points to 1,911 points, and so set an international milestone as the largest-ever such share price decline in history. That is, the burst of the periodically collapsing bubble was without precedent. With limitations on short selling, the stock price reveals mainly good news, such as the split-share reform and the expectation of renminbi appreciation. When the hidden bad news was released comparatively suddenly, stocks didn't just drop - they dropped heavily (Chen and Zhang 2009).

\section{The new bubble period (May 2014 - July 2015)}

The GSADF test helped us to identify a second periodically collapsing bubble that was already forming in early 2014. On the last trading day of 2013, the Shanghai A-share price index closed at 2,116 points. This was the fourth consecutive year that the Shanghai A-share stock market ended lower than it had started. From May 2014, it had started to rise again and, from mid-2014 to June 2015, the A-share stock price grew from 2,121 points to 5,056 points, or 138.3 per cent.

There are several sources of this recent rally. First, after the subprime crisis, China retained a steady economic growth rate, while the growth rate of many economies, especially high-income ones, fell significantly during the crisis and have not recovered. This climate of higher macroeconomic growth has provided favourable conditions for the rise of the A-share index. Meanwhile, the PBC, as China's central bank, has, since the subprime crisis, imposed policies for monetary easing and to encourage loose credit (Song et al. 2015). Such policies increased market liquidity, which helped the A-share stock market rebound. Additionally, the CSRC introduced new policies in 2014, including reform of 
the securities issuance system, approving the issuance of preferred stock and opening Shanghai-Hong Kong Stock Connect-all of which helped to boost confidence in the stock market.

The Shanghai A-share stock price had climbed to 5,166 points by mid-June 2015, and many individual investors hoped it would return to 6,000 points as in 2007. But, by 19 June, the Shanghai A-share market had fallen below 4,500 points to close at 4,478 points; the weekly decline was as high as 13.32 per cent, making this the biggest weekly decline since 2008. Until 3 July, the Shanghai A-share market continued to fall, closing at 3,686 points.

These trends are similar to those during the burst of the previous periodically collapsing bubble, though there are some new characteristics. The problem of an overly high PE ratio is particularly prominent. The PE ratio of the Shanghai A-share stock market was up 22 times by June. In general, a high PE ratio represents high valuation. If there is not a proper ROE matching the PE ratio, the Shanghai A-share stock market should, with high probability, fall. Again, the newly opened stock accounts in the first half of 2015 were close to those of 2007. Under China's high-leverage stimulus, herding behaviour drives many institutional investors to sell their shares. When the stock index falls, the leveraged funds might be required to liquidate.

The two periodically collapsing bubbles identified by the GSADF test have many similarities in their formation, development and bursting phases. Bubbles often appear when a stock market has sufficient liquidity. Initially, the existence of a bubble promotes the value of the stock market. Thereafter, a high PE ratio and turnover rate and some irrational behaviour induce the bubble to gradually inflate until it is out of control. Ultimately, bad news or a sudden market crisis will rapidly puncture the bubble and destroy the false prosperity of the stock market.

\section{Conclusion}

Our study using the GSADF test confirms the two prominent episodes of exuberance and collapse in the Shanghai A-share stock market, while the SADF test finds only a single bubble. The empirical test results, in other words, suggest that the GSADF test is, in practical terms, better than the SADF test to detect multiple bubbles.

The evolution of the periodically collapsing bubbles are analysed in depth. The first bubble revolves around the subprime mortgage crisis between October 2006 and January 2009. The second is a more recent bubble, extending 
from May 2014 to July 2015. These have many common characteristics in terms of the process of bubble formulation, development and the bursting phase, such as a high PE ratio, high turnover and some irrational behaviour.

In sum, this chapter confirms two bubbles in the Shanghai A-share stock market retrospectively using the GSADF test. The use of these results for understanding past bubbles in the Shanghai A-share stock market is significant and meaningful; however, this method can only be employed to identify previous bubbles. Further research may wish to explore methods to predict future bubbles.

\section{References}

Ahmed, E., Rosser, J. B. and Uppal, J. Y. (1999), Evidence of nonlinear speculative bubbles in Pacific-Rim stock markets, The Quarterly Review of Economics and Finance, 39(1): 21-36.

Blanchard, O. J. (1979a), Backward and forward solutions for economies with rational expectations, The American Economic Review, 69(2): 114-118.

Blanchard, O. J. (1979b), Speculative bubbles, crashes and rational expectations, Economics Letters, 3(1979): 387-389.

Blanchard, O. J. and Watson, M. W. (1982), Bubbles, rational expectations and financial markets, NBER Working Paper Series No. 945, Cambridge, Mass.: National Bureau of Economic Research.

Campbell, J. Y. and Shiller, R. J. (1988), The dividend-price ratio and expectations of future dividends and discount factors, The Review of Financial Studies, 1(3): 195-228.

Chen, G. J. and Zhang, Y. J. (2009), Heterogeneous beliefs, short sale restriction and China's stock market plunge phenomenon research, Finance Research, 346(4): 80-91.

Diba, B. T. and Grossman, H. I. (1988a), Explosive rational bubbles in stock prices?, The American Economic Review, 78(3): 520-530.

Diba, B. T. and Grossman, H. I. (1988b), The theory of rational bubbles in stock prices, The Economic Journal, (98): 746-754.

Evans, G. W. (1991), Pitfalls in testing for explosive bubbles in asset prices, The American Economic Review, 4(81): 922-930.

Flood, R. P. and Garber, P. M. (1980), Market fundamentals versus price-level bubbles: The first tests, Journal of Political Economy, 88(4): 745-770. 
Flood, R. P. and Hodrick, R. J. (1990), On testing for speculative bubbles, Journal of Economic Perspectives, 4(2): 85-101.

Gurkaynak, R. S. (2008), Econometric tests of asset price bubbles: Taking stock, Journal of Economic Surveys, 22(1): 166-186.

Hall, S. G., Psaradakis, Z. and Sola, M. (1999), Detecting periodically collapsing bubbles: A Markov-switching unit root test, Journal of Applied Econometrics, (14): 143-154.

Homm, U. and Breitung, J. (2012), Testing for speculative bubbles in stock markets: A comparison of alternative methods, Journal of Financial Econometrics, 10(1): 198-231.

Hu, C. S. and Wang, Y. F. (2013), Noise trading and stock returns: Evidence from China, China Finance Review International, 3: 301-315.

Kang, Z. Y. (2010), Chinese stock market bubbles test based on STAR model, Academic Monthly, 42(12): 83-89.

Lehkonen, H. (2010), Bubbles in China, International Review of Financial Analysis, (19): 113-117.

Phillips, P. C. B., Shi, S. P. and Yu, J. (2013), Testing for multiple bubbles: Historical episodes of exuberance and collapse in the $S \& P$ 500, Economics \& Statistics Working Paper Series No. 4, July, Singapore: Singapore Management University.

Phillips, P. C. B., Shi, S. P. and Yu, J. (2014), Specification sensitivity in righttailed unit root testing for explosive behaviour, Oxford Bulletin of Economics and Statistics, 76(3): 315-333.

Phillips, P. C. B., Wu, Y. and Yu, J. (2011), Explosive behavior in the 1990s Nasdaq: When did exuberance escalate asset values?, International Economic Review, (52): 201-226.

Shiller, R. J. (1981), Do stock prices move too much to be justified by subsequent changes in dividends?, American Economic Review, (71): 421-436.

Song, L., Garnaut, R., Fang, C. and Johnston, L. (2015), China's domestic transformation in a global context, Canberra: ANU Press.

Tan, L., Chiang, T. C., Mason, J. R. and Nelling, E. (2008), Herding behavior in Chinese stock markets: An examination of A and B shares, Pacific-Basin Finance Journal, (16): 61-77. 
Taylor, M. P. and David, A. P. (1998), Periodically collapsing stock price bubbles: A robust test, Economics Letters, (61): 221-228.

West, K. D. (1987), A specification test for speculative bubbles, The Quarterly Journal of Economics, 102(3): 553-580.

Wu, Y. R. (1997), Rational bubbles in the stock market: Accounting for the US stock-price volatility, Economic Inquiry, April: 309-319.

Yu, M., Pi, D. Y. and Zhou, R. X. (2013), A study on speculative bubbles test by using variance decompositions methods in the Chinese stock market, Economy and Management, 27(11): 40-45. 
This text is taken from China's New Sources of Economic Growth: Reform, resources and climate change, Volume 1, edited by Ligang Song, Ross Garnaut, Cai Fang \& Lauren Johnston, published 2016 by ANU Press, The Australian National University, Canberra, Australia. 